\title{
PI3K p110beta/delta Inhibitor KA2237
}

National Cancer Institute

\section{Source}

National Cancer Institute. PI3K p110beta/delta Inhibitor KA2237. NCI Thesaurus. Code

C126271.

A dual selective inhibitor of the beta and delta isoforms of the $110 \mathrm{kDa}$ catalytic subunit of class I phosphoinositide-3 kinase (PI3K-beta/delta), with potential antineoplastic activity. PI3K-beta/delta inhibitor KA2237 selectively inhibits the PI3K-beta and -delta isoforms and prevents their activation, which inhibits PI3K-beta/delta-mediated signal transduction pathways. This decreases proliferation and induces cell death in susceptible tumor cells. Unlike other isoforms of PI3K, PI3K-beta and -delta are overexpressed primarily in solid and hematological tumor cells and play crucial roles in tumor cell survival, and immunoregulation. The targeted inhibition of these PI3Ks allows this agent to potentially be more efficacious and less toxic than pan PI3K inhibitors, which also affect normal, healthy cells. 